\title{
ALGUNAS CONSIDERACIONES POLÍTICO-CRIMINALES PREVIAS A LA INCRIMINACIÓN DEL TRÁFICO DE PERSONAS*
}

\author{
ANA ISABEL PÉREZ CEPEDA \\ Profesora Titular de Derecho Penal \\ Universidad de La Rioja
}

En memoria de Alexandro Baratta, un maestro

SUMARIO

I. INTRODUCCIÓN. II. LA INMIGRACIÓN Y LA TRATA DE SERES HUMANOS COMO FENÓMENOS ESTRUCTURALES EN LA GLOBALIZACIÓN. III. LA TRASNACIONA-LIZACIÓN O GLOBALIZACIÓN DEL CRIMEN. IV. DIFERENTES FINALIDADES CONTEMPORÁNEAS DEL TRÁFICO O TRATA DE SERES HUMANOS EN EUROPA. V. LA POLÍTICA MIGRATORIA Y LA INMIGRACIÓN CLANDESTINA

* Este artículo es una parte del primer capítulo de un libro que aparecerá en los próximos meses titulado Globalización, tráfico ilícito de personas y Derecho penal. Esta investigación, realizada en su mayoría en la Universidad de Bologna (Italia), gracias a la beca para estancias de investigadores, profesores de universidad españoles en centros de investigación extranjeros, concedida por el Ministerio de Educación, se desarrolla en el marco de un proyecto de I+D que bajo el título "Ciudadanía y participación: una investigación socio-jurídica de los problemas identitarios en la sociedad del Siglo XIX”, se ejecuta en la Universidad de La Rioja. 


\section{INTRODUCCIÓN}

En el siglo XXI la esclavitud no es una monstruosidad del pasado de la cual nos hayamos definitivamente liberado, se trata de un negocio que en el mundo está más en auge que nunca. La globalización, la pobreza, el aumento demográfico de los países de origen, la violencia social, la inestabilidad política de los Estados, los conflictos étnicos o religiosos, el ejercicio autoritario del poder, la modernización de la agricultura, etc... tienen gran impacto en la permanencia de la esclavitud, además se trata de un fenómeno favorecido por la inmigración económica y la vulnerabilidad de los inmigrantes.

Hasta hace poco tiempo, este nuevo fenómeno era una forma esclavitud invisible, en la medida en que ninguno de los medios de control social existente en nuestras sociedades adoptaban medidas al respecto. Sin embargo, ha ido tomando una progresiva relevancia en política internacional nunca desarrollada en años anteriores, dada la gravedad que ha adquirido el fenómeno del tráfico de personas en el ámbito mundial, en la segunda mitad de los años noventa. Las principales razones para este cambio se deben $a^{1}$ :

a) Que se incluye este tema dentro de la política migratoria que ocupa un lugar prioritario en la agenda política de los gobiernos occidentales, como consecuencia del aumento de los flujos migratorios provenientes, en particular de Europa del Este, de África, de América Latina, del Medio Oriente y de Asia. En otras palabras, dado el carácter ilícito de los flujos migratorios y de la implicación en su gestión de la criminalidad organizada internacional se aborda el tema como una cuestión de seguridad nacional e internacional.

b) Que se ha aumentado la atención investigadora y judicial, nacional e internacional, con relación a la trata de mujeres para fines de explotación sexual.

c) Una particular atención de los medios de comunicación de masas a los fenómenos de la "invasión" de los inmigrantes clandestinos y a la trata de mujeres para fines de explotación sexual.

Entre nuestras fronteras, el hecho de que a partir de los años 80, el Estado español se haya trasformado en un país de emigración, en particular, desde el inicio de los años noventa, ha visto progresivamente aumentar el ingreso ilegal de inmigrantes en el territorio nacional, convirtiéndose por su posición geográfica en un país de destino y también en un país de paso obligatorio para arribar a otros países europeos. Ha motivado una reciente preocupación, alimentándose desde el gobierno una alarma de que es necesario responder en términos institucionales, con acciones preventivas, pero sobre todo represivas concretas.

En contra de esta línea y desde el convencimiento de que ninguna ley, sea rígida o flexible, va a cambiar las tendencias profundas del fenómeno migratorio. A mi entender, la inmigración tiene que ver con las necesidades de mano de obra barata por parte de los sectores productivos, y, en términos generales, con el expolio y desvertebración de los países del llamado "tercer Mundo", junto a las tremendas desigualdades entre países ricos y países pobres. Es por ello que, comparto la creencia

${ }^{1}$ La Commissione Parlamentare d' inchista sul fenómeno della mafia e delle altre asociación criminali similari, Relazione sul traffico degli esseri umani, aprovata dalla Comissione in data 5 dicembre 2000, págs. 13 y s. 
de que las políticas represivas, policiales, de cierre de fronteras a cal y canto, no harán otra cosa que aumentar el sufrimiento humano y profundizar en las injustas relaciones Norte-Sur.

En efecto, entiendo que el gran debate ideológico, el debate de fondo, ha de mirar no tanto a los efectos sino a las causas, por ello, en este artículo, me propongo analizar globalmente todo este fenómeno del trafico internacional ilegal de personas, que comprende: por una parte, todas aquellas conductas delictivas que favorecen la inmigración clandestina (smuggling of migrants, literalmente contrabando de inmigrantes), por la otra, tenemos el tráfico de personas con la finalidad de explotación sexual, laboral, en mendicidad o cualquier otro fin degradante (introducir droga, venta de órganos etc.), que se denomina tráfico o trata de seres humanos (traffking of human being).

Hoy nadie discute que, frente a este nuevo mercado criminal, surge la necesidad de la existencia de preceptos penales que impidan el tráfico de inmigrante, la sobreexplotación laboral, sexual o por parte de las mafias - que encuentran su mejor caldo de cultivo en las políticas prohibicionistas y de corte represivo-y que garanticen, por el contrario, la seguridad jurídica y la igualdad de derechos de quienes viven y trabajan en nuestros territorios, como corresponde a un Estado Democrático y de Derecho, siendo éste el mejor antídoto contra la injusticia y la segregación social que padecen los inmigrantes. Pero, este tráfico de personas es un conflicto social que se manifiesta como problema estructural, incrementado o fruto de la globalización. Ante esta situación, no se puede pretender atajar el problema exclusivamente con medidas represivas, es decir, a través de una huida hacia el Derecho penal, dado que por desgracia, existe una realidad que se nos muestra como infranqueable; en las funciones de regulación o control relativas a la sociedad global, el Derecho penal sólo puede ejercer sus fines en un sentido metafórico. De ahí que, debamos ocuparnos sobre todo en el análisis de las manifestaciones y causas de este tipo de criminalidad para poder prevenirla. Adelantando, desde un primer momento que, arribaré a la conclusión de que la prevención del tráfico de seres humanos y de otros tipos de criminalidad, como señaló, el recientemente desaparecido BARATTA, sólo se puede conseguir a través de "la lucha contra la exclusión social y contra los mecanismos deshumanos y esclavistas de acumulación impuesta de la globalización neoliberal de la economía; una lucha por una sociedad basada en la realización de las necesidades reales, esto es la potenciación del desarrollo de los individuos y de los pueblos"2.

\section{LA INMIGRACIÓN Y LA TRATA DE SERES HUMANOS COMO FENÓMENOS ESTRUCTURALES EN LA GLOBALIZACIÓN}

Una de las claves por la que pervive el tráfico de seres humanos se encuentra, como he señalado antes, en que la mundialización se ha desarrollado en un mundo marcadamente desigualitario, bajo unas relaciones de poder claramente asimétricas, propiciando un sistema de intercambios desiguales entre países y acentuando la dominación de la clase y género preexistentes. Fruto de esta dinámica aparece la

\footnotetext{
${ }^{2}$ BARATTA A., "Diritto alla sicurezza e sicurezza dei diritti?, en Democracia e diritto 9/2001, pág. 23.
} 
globalización, que intenta enmascarar este carácter asimétrico y desigualitario de la mundialización, presentando a ésta como un proceso de aproximación creciente e irreversible hacia una única sociedad planetaria, en la que todos tendríamos una única identidad, la de "ciudadanos del mundo", una única cultura, la difundida por los massmedia. La industria de la cultura global significa cada vez más la convergencia de los símbolos culturales y de formas de vida. Está surgiendo un sólo mundo, un único mundo mercantil y pertenecemos a una única "clase", la de los consumidores. Si el individuo no es un sujeto consumidor, no existe o no cuenta en las nuevas relaciones jurídico-económicas trasnacionales. De esta manera la capacidad de consumir se convierte en un criterio de integración o de exclusión social ${ }^{3}$, generado polarización y asimetrías. Las desigualdades globales son cada vez más evidentes y manifiestas, creando dos nuevos estatus de seres humanos, el estatus de los incluidos en una economía globalizada y flexibilizada o de apartidas, carentes de identidad, como consecuencia de su falta de competencia económica y de su imposibilidad para acceder a los mercados de consumo.

Todo ello se desarrolla en un único contexto regido por el Mercado, que se convierte así en el gran igualador y el gran separador de la sociedad. En este sistema capitalista mundial, donde domina el imperativo de competir en el mercado global sin necesidad de reformular las condiciones de gestión democrática de la sociedad global, la globalización revela su estrategia restar poder a la política estatal-nacional, para conseguir "la realización de la utopía del anarquismo mercantil del Estado mínimo". . El globalismo es la ideología del dominio del mercado mundial o la ideología del liberalismo, reduciendo la globalización a una dimensión, la económica ${ }^{5}$. Así, nos encontramos ante el capital, que es transnacional a través de las fusiones y flujos. A este movimiento de capital global no sólo se han sustraído a la intervención fiscal del Estado, sino que además pueden amenazar con hacer uso de su opción de salida cuando desde un gobierno se implanten condiciones gravosas para la inversión intentando proteger los valores sociales y preservar la seguridad en el empleo. Pues bien, también responde a un principio de libre circulación a escala mundial el mercado de nuevas tecnologías, la mayor parte de materias primas y de mercancías manufacturadas ${ }^{6}$.

En paralelo al proceso emergente de una escala planetaria para la economía, la finanza, el comercio y la información, viene inmerso el movimiento de otro proceso,

${ }^{3}$ En esta línea, vid., FARIÑAS DULCE, M.J., Globalización, ciudadanía y Derechos humanos, en Cuadernos "Bartolomé de las Casas”, DYKINSON, 2000, pág. 27

${ }^{4}$ BECK U., ¿Qué es la globalización?, Falacias del globalismo, respuestas a la globalización, Paidós, Estado y sociedad, 2001, pág. 17

${ }^{5}$ El núcleo ideológico del globalismo reside, según BECK U., ¿Qué es la globalización?, Falacias del globalismo, respuestas a la globalización, op. cit., pág. 27, en dar al traste con una diferencia fundamental entre política y economía. El globalismo pretende que un edificio tan complejo como Alemania, es decir estado, sociedad, cultural, política exterior debe ser tratado por una empresa. Se trata de un imperialismo económico bajo el cual las empresas exigen las condiciones básicas en las que optimizar sus recursos.

6 Ante esta situación, el estado-nación se muestra impotente, como señala CASTELLS, M.," La era de la información: Economía, Sociedad y Cultura” en El poder de la identidad, Volumen II, ALIANZA, Madrid, 1998, pág. 282, "para controlar la política monetaria, decidir su presupuesto, organizar la producción y el comercio, recabar los impuestos sobre la sociedades y cumplir sus compromisos para proporcionar prestaciones sociales. En suma se ha perdido parte de su poder económico". Es esto lo que explica que las instituciones y organismos supraestatales, en el ámbito mundial o en grandes áreas económico-políticas, estén asumiendo competencias que hasta hace poco eran exclusivas de los Estados. 
que impone los vínculos espaciales, que es lo que se llama <<localización〉>. El ejemplo más palpable es que la fuerza del trabajo queda fuera de esta dinámica globalizadora. Es aquí donde la lógica del sistema se muestra más incoherente, dado que si los economistas han insistido siempre en que el trabajo es uno de los factores de clásicos en la función de producción, su comportamiento debe ajustarse a la misma lógica que el resto de factores, no sólo para determinar su redistribución sino también para explicar su movilidad ${ }^{7}$. Sin embargo, el factor trabajo es, con mucho, el que menor grado de libertad de movimientos conoce, puesto que en esta parcela del mercado se pretende una dinámica a la inversa a través de la multiplicación de barreras a su libre circulación ${ }^{8}$. Los gobiernos han perdido el control sobre el capital, pero controlan férreamente las fronteras de los trabajadores. Bien podemos decir que, entre todos los factores y recursos el único que permanece nacional es el trabajo, puesto que aunque progresivamente la idea de los visados de ingreso viene abolidas en todo el mundo, no sucede lo mismo con el control de pasaporte9. La abolición de los visados de ingresos se une a la mayor rigidez de los controles de inmigración, lo cual produce una nueva estratificación social en función de la posibilidad de los sujetos de tener acceso o no a la movilidad global, así mientras que algunos gozaran de la nueva libertad de los sin papeles, otros podrán desplazarse libremente.

Como señala BAUMANN ${ }^{10}$, si para el primer mundo, el mundo de que es movible su escala global, el espacio ha perdido su cualidad de vínculo, tanto en su versión real como en su versión virtual. Para el segundo mundo, aquellos a los que les es legada una localidad, les está prohibido moverse, constreñidos, por ello, a soportar de modo pasivo cualquier cambio de lugar que les es legado, el espacio real se va rápidamente restringiendo. Se trata de un tipo de privación que es ahora más dolorosa nunca, dada la ostentación con la que los medios muestran la conquista del espacio y la virtual accesibilidad al mismo, sin embargo en la realidad no virtual permanece obstinadamente inalcanzable ${ }^{11}$.

Además, en el supuesto de que logren traspasar las fronteras, no podemos obviar el factor de que en este primer mundo la economía global necesita cada vez menos mano de obra, mientras el mercado de los inmigrantes se multiplica y engrandece ${ }^{12}$. Y ello es así, porque antes los viejos ricos necesitaban de los pobres para hacerse ricos y mantenerse como ricos. Ahora, aunque en el territorio de los países desarrollados se entiende que la explotación de los más pobres en su mayoría inmigrantes también sirve; sin embargo cada vez se requiere una cantidad decreciente y siempre menor. Es decir,

\footnotetext{
${ }^{7}$ Vid., ABAD MÁRQUEZ, L. V., “Globalización, demografía y migraciones internacionales”, en Sociedad y Utopía, Revista de ciencias sociales, 2000, pág. 57.

${ }^{8}$ Vid., más ampliamente, MORENO, I., "Mundialización, globalización y nacionalismos: la quiebra del modelo Estado- Nación”, en Los nacionalismos: globalización y crisis del Estado-Nación, Cuadernos del Consejo General del Poder Judicial, 1998, págs. 11 y ss.

${ }^{9}$ Como ha afirmado BAUMAN, Z., Dentro de la Globalizzazione. Le conseguenze sulle persone, Laterza, 1999, págs. 97 y ss.: "todos ellos pueden ser parte de los nómadas, en los hechos o en las esperanzas, pero existe un abismo difícil de superar entre la experiencia que se pueden tener, respectivamente, al vértice de la escala de libertad. El término de moda nómada, aplicado indiscriminadamente a todo los que viven en la era postmoderna, induce a un grave error: no hay ninguna luz de hecho sobre la enorme diferencia que separa los dos tipos de experiencia..."

${ }^{10}$ Ibídem.

${ }^{11}$ Ibídem

${ }^{12}$ Vid., SARTORI, G., Pluralismo, multiculturalismo e estranei. Saggio dulla società multietnica, RCS Libri, 2002, pág. 147 y ss.
} 
la mano de obra inmigrada sólo resulta necesaria en los sectores como la agricultura, construcción, turismo, servicio doméstico, prostitución, etc., dado que en el caso de las empresas trasnacionales (ETN), resulta más rentable y con menos riesgos que trasladarse a aquellos países donde los costes sociales son más bajos. El trabajo en algunos lugares del mundo donde se asientan las ETN es desarrollado en estado de esclavitud, reduciendo el costo de los bienes que se producen e incrementando los beneficios, de tal manera que las empresas erradicadas en Europa o América del norte no pueden competir con estas ETN. Lo dicho demuestra no sólo que la esclavitud contribuye a la economía mundial, sino que en cualquier parte que se produzca el trabajo de los esclavos supone una amenaza para los puestos trabajo de todo el mundo ${ }^{13}$.

Este fenómeno pone de manifiesto que nos encontramos ante un derecho global sin Estado o el derecho del capital global ${ }^{14}$, creándose las condiciones optimas para que las empresas trasnacionales ETN compitan entre sí como nuevos señores feudales, violando impunemente los derechos humanos más elementales y atentando acumulativamente contra los recursos ecológicos y culturales mundiales sin ningún mecanismo de control. Los problemas para romper con esta nueva tendencia, como denuncia FARIÑAS DULCE, son esencialmente dos $^{15}$ : el primero es que, frente a las nuevas violaciones de los derechos humanos los países periféricos o semiperiféricos se encuentran en la actualidad limitados en su capacidad de actuación; por la situación económica que padecen no criminalizan los comportamientos de explotación con el fin de que la reducción de los costes atraiga hacia ellos el flujo de inversiones. Además, el caos de actividad, la violencia y corrupción producto del cambio económico, está destruyendo las reglas sociales y los tradicionales vínculos de responsabilidad que podrían proteger a los potenciales esclavos. El problema reside en que la ausencia de respuestas a la exclusión hace ilusoria cualquier prevención primaria, pero el deterioro del servicio de seguridad y su participación en el llamado crimen organizado y en la corrupción degrada también la prevención secundaria ${ }^{16}$. El segundo surge cuando constatamos que las organizaciones sindicales de los trabajadores siguen ancladas en la esfera estrictamente estatal-nacional y burocrática, lo que ocasiona una importante crisis representativa que imposibilita contrarrestar el poder o al menos controlar a las empresas trasnacionales.

En cualquier caso, conviene tener presente, como señalábamos antes que "la nueva esclavitud" se ha convertido en una actividad económica internacional porque no sólo se da en determinadas áreas geográficas del planeta, donde se desplazan las ETN para aprovecharse de ella, abaratando sus costes, sino que también podemos encontrar en este "primer mundo" en ámbitos como la prostitución, la agricultura, el servicio doméstico, la construcción, la industria textil, etc., lo que refleja que en la economía actual la esclavitud está pasando de formas culturalmente específicas y localizadas a una

${ }^{13}$ BALES, K., I nuovi schiavi. La merce unamana nell'economia globale. Saggi Universale Economica Feltrinelli, 2002, págs. 26 y ss. Para una descripción de cómo actúan estas ETN, vid., págs. 223 y ss.

${ }^{14}$ FARIÑAS DULCE, M.J., Globalización, ciudadanía y Derechos humanos, op. cit., pág. 31

${ }^{15}$ Para mayor profundización, vid., FARIÑAS DULCE, M.J., Globalización, ciudadanía y Derechos humanos, op. cit., págs. 23 y ss.

${ }^{16}$ ZAFFARONI, E.R., "La globalización y las actuales orientaciones de la política criminal", ejemplar mecanografiado de una conferencia pronunciada en el $2^{\circ}$ Seminario Internacional de Derecho penal organizado por el Centro de Estudios de Política Criminal y Ciencias penales en México, 1999, pág. XIV 
nueva forma emergente estandarizada o globalizada. En efecto, por todos es conocida la existencia de una economía sumergida que demanda mano de obra y fomenta la existencia de redes destinadas al tráfico ilícito de personas. Las condiciones laborales para estos inmigrantes son: sueldos de miseria $^{17}$, generalmente sin contrato y sin derechos, en condiciones de seguridad e higiene laborales ilegales para los nacionales y con jornadas amplísimas. La situación de irregularidad en la que vive el inmigrante tiene su origen no sólo en el agravamiento de los factores expulsivos, sino también en los respectivos marcos legales de los países desarrollados que regulan las condiciones de ingreso legal, en la medida en que son excesivamente restrictivas. De esta forma, se determinan las condiciones estructurales para la consolidación de un grupo social, constantemente marginalizado, permanentemente bajo control y socialmente precario, además al estar continuamente amenazado del espectro de la exclusión y la clandestinidad: al inmigrante no le quedan muchas alternativas: el trabajo clandestino, la microcriminalidad y la nueva esclavitud. Parece que, en esta económica global guiada por la búsqueda de los beneficios, el peso de la dignidad de los individuos disminuye hasta la perdida de derechos. Los derechos del Hombre y la mundialización se encuentran en una situación cada vez más compleja y contradictoria.

En efecto, la lógica utilitarista y acumulacionista del capitalismo global repercute económicamente sobre los niveles de protección de los denominados derechos sociales, económicos y culturales y de los derechos colectivos en general, perjudicando, por tanto, a los estratos sociales más desprotegidos económica, social y culturalmente. En otras palabras, el fundamentalismo del mercado radicaliza el dogma del equilibrio del mercado y lo absolutiza, socavando el poder popular y desmantelando el Estado de bienestar. Ello es así, en la medida en que los mecanismos de flexibilidad productiva y desregularización jurídica están produciendo un descenso de las remuneraciones económicas y en las garantías sociales de los trabajadores, así como la destrucción de puestos de trabajo. El retroceso de los derechos de carácter social y reedistributivo provoca un creciente empobrecimiento económico y cultural de la población, así como una marginación y estigmatización de amplios sectores sociales, que son los que van quedando excluidos del mercado social del trabajo y del consumo, con los consiguientes mecanismos de exclusión y de falta de solidaridad intergeneracional, que dicho proceso conlleva $^{18}$. Siguiendo esta tendencia el Derecho penal, en su función de última ratio, se inhibe ante las más graves infracciones en este ámbito, con lo que no sólo está respondiendo ante los requerimientos de las desregularización, sino que además se está introduciendo elementos determinantes de la decisión económica ${ }^{19}$.

La visión hasta el momento analizada de la globalización desvela que el proceso global termina siendo una <<glocalización〉>, esto es, fundamentalmente un nuevo reparto a la vez de privilegios y ausencia de derechos, riqueza y pobreza, posibilidades

${ }^{17}$ En un reciente estudio realizado por la policía en Berlín, se demuestra que un inmigrante ilegal gana diez veces menos que uno local, un estudio más detallado, vid., GHOSH, B., Huddles masses and uncertain schores: insights into iregular migration, The Hague, Martinus Nijhoff Publishers (Kluwer) 1998, pág. 53.

${ }_{18}$ Más ampliamente, vid., FARIÑAS DULCE, M.J., Globalización, ciudadanía y Derechos humanos, op.cit., pág.19

${ }_{19}$ Así, se ha pronunciado, TERRADILLOS BASOCO J., El derecho de la globalización luces y sobras", en Trasformaciones del Derecho en la mundialización, Consejo General del Poder Judicial, Madrid, 1999, pág. 209; el mismo "El Estado y los conflictos sociales: la función del sistema penal", en Revista de Derecho Social, nº 9, 2000, pág. 29 
de triunfo y falta de perspectivas, poder e impotencia, libertad y falta de libertad ${ }^{20}$. Puede afirmarse que, la globalización y la localización son sólo son dos momentos o caras de la misma moneda; son al mismo tiempo fuerzas impulsoras y formas de expresión de una nueva polarización y estratificación de la población mundial en ricos globalizados y pobres localizados. Así lo que aparece como conquista de la globalización para algunos, representa una reducción a la dimensión local para otros, es decir, lo que para unos es libre elección, para otros es un destino implacable y cruel $^{21}$. En suma, parece que es un hecho difícilmente rebatible que el proceso globalizador está dualizando las estructuras económicas y está consolidando un mundo con dos visiones y una humanidad con dos dimensiones: una la de los países desarrollados que acumulan cada día mas riqueza y capital, otra la de los países en vías de desarrollo que están cada vez más hundidos en la pobreza, sumisión y explotación ${ }^{22}$. La miseria y la situación deplorable de los países son consideradas como los factores deficitarios de la elección del modelo de vida de la población y la inmigración aparece como una estrategia de respuesta a esta pobreza, lo que está provocando movimientos masivos de personas frente a los que valen poco todos los esfuerzos por impermeabilizar las fronteras.

Ante esta situación, los gobiernos estatales ${ }^{23}$, que ya no gobiernan, sino que sólo gestionan las consecuencias negativas del proceso de globalización económica, con las limitaciones impuestas por la necesidad de tener que propiciar las condiciones favorables para la valorización del capital inversor, es decir, con los condicionamientos fácticos de un predominio casi absoluto del mercado financiero en detrimento del trabajo global. En lugar de implementar mecanismos regionales de integración global, que lleguen a ser capaces de articular algún tipo de medidas de control y de organización frente a las transacciones económicas trasnacionales, así como procurar la vigencia de los derechos humanos en todo el mundo, han decido que la solución para preservar la seguridad, nuestro mercado laboral y Estado de bienestar pasa por imponer numerosas trabas legales y policiales frente a los inmigrantes pobres. Con ello, pretenden controlar los flujos migratorios, lo que no sólo ahonda en las estrategias de dualización y dependencia en las que se mantiene a los países del Sur, sino que además en la medida en que el número de pobres aumenta sin parar y caen en una situación cada vez más desesperada, fruto de una existencia sin perspectivas, la movilidad y la misma libertad de movimiento aparece como una mercancía escasa y distribuida de manera

${ }^{20}$ Vid. BECK U., ¿Qué es la globalización?, Falacias del globalismo, respuestas a la globalización, op. cit., pág. 88

${ }^{21}$ Más ampliamente, BAUMAN, Z., Dentro de la Globalizzazione. Le conseguenze sulle persone, Laterza, 1999, pág.4.

${ }^{22}$ Según el Informe sobre el desarrollo mundial 2000-2001: lucha contra la pobreza del Banco Mundial, más de 2.800 millones de seres humanos viven con menos de 2 dólares de renta al día, y más de 1200, con menos de un dólar diario. Y mientras tanto, La Ayuda Oficial que destinamos el conjunto de países de la OCDE ha disminuido la pasada década del 0.36 por ciento al 0.24 por ciento del PIB.

${ }^{23}$ Para HABERMAS, J., "El estado-nación europeo y las presiones de la globalización”, en New Left Review, n¹ ("El nacionalismo en tiempo de globalización”) febrero 2000, pág. 124, se ha producido una erosión de las prerrogativas del Estado-nación que se manifiesta en: "a) el declive de los recurso del estado para efectuar tareas de control; b) los crecientes déficit de legitimación de los procesos de toma de decisiones; y c) una creciente incapacidad de desempeñar el género de funciones directivas y organizaciones que contribuyen a asegurar la legitimidad". 
desigual, lo que se convierte en el principal factor de estratificación social de nuestros tiempos, que podemos definir postmodernismo ${ }^{24}$.

Pero es que además, no podemos obviar que ni siquiera en este primer mundo, como señala DE LUCAS, los denominados derechos sociales están al alcance de todos los seres humanos, de ello se encargan las respectivas legislaciones. Ello ha provocado que se alcen algunas voces demandando que es esencial que en los países de acogida pongan en práctica políticas de integración que impidan que se cree en el Norte un Cuarto Mundo de explotación y marginación. La integración social económica de los inmigrantes es un problema de derechos fundamentales, sin embargo, estos derechos sólo son reconocidos a un sector mínimo (una parte del norte, el norte del norte, el norte del sur) que pueden permitirse el lujo de ser nómadas y de pagarse las mercancías en que se han convertido el resto de derechos ${ }^{25}$. Se produce una disociación entre los derechos individuales y políticos, por una parte, y los derechos económicos, sociales y culturales, por la otra, a los cuales se les pretende vincular de la ciudadanía y desvincular del propio catálogo formal de derechos humanos. Con la consecuencia de que se genera también una ausencia de compromiso con las normas estatales internas, así como con las responsabilidades colectivas, lo que se convierte en un factor de desintegración social, al dejar fuera de los vínculos sociales un amplio margen de la población, que automáticamente pasan a convertirse en los nuevos parías de la civilización global.

Arribamos así a la conclusión de que la globalización presupone discriminación y exclusión. Dicha exclusión estructural no puede por menos generar respuestas violentas y reacciones proteccionistas, en la medida en que se aprovecha la mínima oportunidad para difundir un rechazo etnocéntrico de la diversidad y el rechazo xenófobo frente a los inmigrantes trabajadores, que como capital extranjero amenaza las condiciones de $\mathrm{vida}^{26}$. En este proceso globalizador, la preocupación por las condiciones de seguridad, se limita la mayor parte de los casos a la seguridad de la propia persona y de los propios bienes, convirtiendo la inseguridad y la incerteza en cruciales aspectos de la vida actual ${ }^{27}$, reduciéndose al final en una obsesión por la ley y el orden público. Esto explica porque en la actualidad la inmigración se presenta a la sociedad como un nuevo riesgo ${ }^{28}$, recurriendo a la estratagema de aumentar la obsesión por la seguridad para justificar el tratamiento de dicho fenómeno sólo en clave de orden público, en lugar de intentar seriamente afrontar el reto de mitigar las causas de dicha inmigración y que pase a ser una cuestión social que requiere planificación y amplias actuaciones de los poderes públicos. De manera tal que, como expone TERRADILLOS BASOCO, es

${ }^{24}$ Vid., BAUMAN, Z., Dentro de la Globalizzazione. Le conseguenze sulle persone, op. cit., pág.4.

${ }^{25}$ En este sentido, vid., DE LUCAS, J., "La lucha contra la discriminación”, en Consolidación de derechos y garantías: los grandes retos de los derechos humanos en el siglo XXI, CGPJ, 1999, pág. 150.

${ }^{26}$ Así, se ha manifestado HABERMAS, J., "El estado-nación europeo y las presiones de la globalización”, op. cit, pág. 127.

${ }^{27}$ BAUMAN, Z., Dentro de la Globalizzazione. Le conseguenze sulle persone, op. cit, pág. 7

${ }^{28}$ Los peligros o riesgos pierden su delimitación espacio-temporal para convertirse en globales y permanentes, de manera que se presenta como factores o fenómenos que resquebrajan los pilares de nuestro tradicional sistema de seguridad. Estos riesgos globales en ocasiones no están a la vista, sino que son ficticios y construidos en el presente con el fin de que las sociedades saciadas y acurrucada en su statu quo experimenten por si mismas el miedo. BECK U., ¿Qué es la globalización?, Falacias del globalismo, respuestas a la globalización, op. cit., págs. 143 y s 
cierto que la desregularización de ámbitos que se sustraen al control político producto de la globalización es parcial, pues existe una doble tendencia político-criminal: por una parte, se da una desregularización con el objetivo principal de propiciar la ampliación de los espacios del poder ligados al capital privado, pero por la otra, se procura "una rígida intervención cuando se trata de asegurar la paz pública requerida por ese mismo mercado. Sin que los resultados del cotejo de los medio empleados para la obtención de esa pax con los exigidos por la dignidad" ${ }^{29}$.

Siguiendo a BARATTA, entiendo que la distancia entre incluido-excluidos determina los estereotipos de diverso y peligroso, el contenido específico del sentimiento de inseguridad de la clase garantizada y una política que se encarga exclusivamente del control de la población reducida a un rol precario del proceso productivo y sin ningún rol. Lo que provoca la paradoja de que la exclusión se eleva con el control del riesgo y a que la seguridad de las garantías que se reduzcan. El resultado es que, en vez de aumentar la seguridad de pocos crece la inseguridad de todos ${ }^{30}$. Además, ninguna fortaleza podrá detener las presiones migratorias sobre las áreas del mundo en las cuales se ha centrado el desarrollo económico. El riesgo de la ilegalidad y de la explotación resultará, respecto a los habitantes del tercer y el cuarto mundo, siempre menor que la propia expectativa de pobreza, sin trabajo, sin tierra: sujetos sin futuro producto de una economía que odia el futuro ${ }^{31}$.

Por tanto, si la exclusión social tiene una raíz global, y a su vez, es el punto de emergencia de los problemas de seguridad, ahora es evidente que toda política de seguridad es ilusoria si no inscribe en una política de desarrollo. El verdadero peligro, como ha advertido BAUMAN, es que el hilo de la comunicación social entre los ricos que se globalizan y los pobres que se localizan se rompa porque entre los ganadores de la globalización, en la parte alta superior, y los perdedores de la globalización, en la parte baja inferior, no existan terrenos o espacios en los que poder luchar por la igualdad y la justicia. Ante este riesgo, provocado por la creciente presión del mercado mundial, parece que ha llegado el momento de someter a un control democrático el proceso globalizador, de buscar nuevas reglas que eviten sus efectos perversos y perjudiciales. Sobre la base de que, la civilización sólo está protegida cuando los derechos tienen validez global ${ }^{32}$, surge el desafío de formular en nuevos términos teóricos y políticos la cuestión de lo trascendental de la justicia social en la era de la globalización, desarrollando una política como administración de un estatus social y una política como proyecto de una sociedad diversa, de una sociedad más justa y más igualitaria. En realidad se trata de poner la economía al servicio del desarrollo humano, además la inseguridad de las sociedades disminuirá en la medida en que aumenta la seguridad por los derechos humanos ${ }^{33}$.

En consecuencia, sin renunciar a una utopía global, este proceso debe ir unido al objetivo de construir un mundo más igualitario y más justo, más equilibrado y equitativo, en el que los derechos humanos ocupen un papel central, sin que queden

\footnotetext{
${ }^{29}$ Vid., TERRADILLOS BASOCO J., "El derecho de la globalización luces y sobras”, op. cit., pág. 216

${ }^{30}$ Vid., BARATTA A., "Diritto alla sicurezza e sicurezza dei diritti?, op. cit., págs. 26 y ss.

${ }^{31}$ Ibídem, pág. 35.

${ }^{32}$ BECK U., ¿Qué es la globalización?, Falacias del globalismo, respuestas a la globalización, op.cit., pág. 134

${ }^{33}$ BARATTA A., "Diritto alla sicurezza e sicurezza dei diritti?, op. cit., pág. 28
} 
marginados los derechos económicos, sociales, culturales, etc. ${ }^{34}$. De tal manera, el flujo de inversiones no debe condicionar las opciones político-criminales, para proteger los bienes jurídicos que impone la expansión del mercado sino que el Derecho penal debe contribuir a escala mundial a la definitiva consolidación y expansión de la tutela jurídico-penal de los derechos humanos ${ }^{35}$. El que se haya asegurado poner fin a la impunidad de autores de delitos de enorme gravedad, como genocidio, crímenes de guerra, desaparición forzada de personas, deportaciones masivas, o tortura, es un primer objetivo que se ha cumplido con la entrada en vigor el 1 e julio del 2002 del Tratado de Roma de 1998 que la constitución de una Corte penal Internacional que enjuiciará dichos delitos, que aunque tipificados en la mayoría de los países no son siempre perseguidos con criterios de competencia jurisdiccional limitada.

\section{LA TRASNACIONALIZACIÓN O GLOBALIZACIÓN DEL CRIMEN}

El fenómeno de la globalización en el ámbito penal se manifiesta a través de una nueva dimensión trasnacional de determinadas formas delictivas. Como señala, TERRADILLOS BASOCO, la globalización del crimen se identifica con la aparición, o proliferación, de manifestaciones criminales organizadas de alcance trasnacional ${ }^{36}$. Dicha globalización del crimen a través de la delincuencia organizada recibe un gran impulso por la mundialización de las comunicaciones, por las transacciones comerciales, económicas y financieras, por el enorme crecimiento de los trasportes internaciones y por el nacimiento de la megalópolis. En otras palabras, los grupos delictivos se sirven de fenómenos contemporáneos como la mundialización, convirtiendo a millones de ciudadanos de todo el mundo en víctimas de sus operaciones. Ello, unido a la impotencia del poder político nacional y de los organismos internacionales frente al económico globalizado se traduce en un creciente dominio del delito económico que tiende a adueñarse de la economía mundial, en la medida en que las actividades económicas adquieren cada día mayor similitud con las prácticas mafiosas $^{37}$. También el hecho de que, debido a la frecuente y masiva emigración, las guerras y los conflictos locales, se hayan esparcido por el mundo minorías étnicas, que viven marginados, representa un terreno fértil para multiplicar la actividad de la criminalidad transnacional. El resultado es que todos los días, el pueblo global se ve afectado insidiosamente por la presencia desestabilizadora del crimen organizado. El impacto negativo de estos grupos en las sociedades pone en peligro la seguridad nacional, la estabilidad económica, política y social, lo que conllevan la necesidad de adoptar políticas preventivas comunes en el ámbito internacional.

\footnotetext{
${ }^{34}$ En este sentido vid., MARTÍNEZ DE PISÓN, J., "Globalización y derechos humanos”, Claves $\mathrm{n}^{\circ} 111,2001$, pág.46.

35 TERRADILLOS BASOCO J., El derecho de la globalización luces y sobras”, op. cit. , 210 y 211

${ }^{36}$ Vid., más ampliamente, TERRADILLOS BASOCO J., "El derecho de la globalización luces y sobras", op. cit., pág. 187. "El Estado y los conflictos sociales: la función del sistema penal”, op. cit., pág. 30

${ }^{37}$ ZAFFARONI, E. R., "La globalización y las actuales orientaciones de la política criminal”, ejemplar mecanografiado de una conferencia pronunciada en el $2^{\circ}$ Seminario Internacional de Derecho penal organizado por el Centro de Estudios de Política Criminal y Ciencias penales en México, 1999, págs. XI y s.
} 
Pero sobre todo plantea que, ante la delincuencia organizada de todo tipo que abarca ámbitos internacionales y que se aprovecha de las posibilidades técnicas globales, las normas nacionales cada vez son menos eficaces. Se avanza cada vez más hacia el vacío al reclamar leyes nacionales en virtud de la igualdad de armas en la lucha contra la delincuencia nacional ${ }^{38}$. Por tanto, la creación y el mantenimiento de un marco viable de lucha conjunta contra la delincuencia transnacional es un reto importante al que se enfrenta la comunidad internacional, en la medida en que los gobiernos no podrán solucionar adecuadamente estos nuevos problemas que surgen si actúan aisladamente o a través de las formas tradicionales de cooperación internacional en materia de prevención del delito. Una estrategia preventiva concertada, más los lazos formales, ofrecen una base de colaboración internacional consolidada contra el crimen. Constatamos así, como la internacionalización de la criminalidad organizada representa un enorme reto pera la creación e internacionalización de la política criminal y penológica en el ámbito de la cooperación internacional, nacional, interregional y bilateral. Si se quiere llevar a cabo políticas de intervención preventivas y represivas, la coordinación con los gobiernos y las autoridades extranjeras es crucial, sólo así podrán intentarse atajar las causas y desarrollarse las acciones internacionales especiales y necesarias con el fin de investigar y reprimir la criminalidad mafiosa. El problema es el carácter paradójico de nuestra situación presente -la afinidad tecnológica y cultural-, se complica ulteriormente cuando se trata de encontrar una afinidad de los sistemas jurídico penales de los diferentes países y regiones, dado que en la dimensión valorativa y factual emerge la realidad unívoca de cada sociedad nacional individual que contradice una creciente interdependencia impuesta por al internacionalización del desarrollo histórico. A pesar de ello, se hace indispensable dar un impulso a una cooperación internacional externa y fluida, que combata eficazmente este tipo de criminalidad a través de una prevención multilateral y bilateral, una cooperación judicial integral y una jurisdicción de alcance global. Ya se han dado pasos a la cohesión, en materia de la extradición, y el traslado en materia penal, el traslado de los condenados y varios acuerdos en el tema de cooperación judicial en el ámbito regional y bilateral.

En cualquier caso ante la gravedad del problema que se plantea, no se puede establecer normas excepcionales, que limiten derechos fundamentales, para facilitar la lucha contra la delincuencia organizada, en la medida en que comporta graves perjuicios al derecho estatal y a la libertad ciudadana, reduce la capacidad de actuación y, en cambio, no combate eficazmente la delincuencia ni contribuye a mejorar la seguridad de los ciudadanos. Las exigencias prácticas de actuación eficaz frente al crimen trasnacional pasan por alto que las demandas que la sociedad dirige al Derecho penal son siempre prácticas. La eficacia socialmente demandada no se identifica con a agravación de las sanciones o la aminoración de garantías, sino con el incremento de resultados preventivos. No cabe articular estrategias que prescindan de una referencia a valores. Lo que supone una ponderación de costes ha de integrar la eventual colisión de cada una de las alternativas con los principios garantizadores que se entienden definidores del sistema ${ }^{39}$. Situados en este debate, no parece que los avances en la lucha contra la delincuencia global se hayan inclinado a un utilitarismo a ultranza

${ }^{38}$ Vid., BECK U., ¿Qué es la globalización?, Falacias del globalismo, respuestas a la globalización, Piadós estado y sociedad, 2001, pág. 189 citando a DÄUBLER-GMELIN H., "Globalisierung geht keineswegs Hand in Hand mit globalem Recht”, en Frankfurter Rundschau, nº 90, (18.04.1997)

39 TERRADILLOS BASOCO J.,"El derecho de la globalización luces y sobras", en Trasformaciones del Derecho en la mundialización, Consejo General del Poder Judicial, Madrid, 1999, pág. 192 
desconocedor de principios garantizadores ${ }^{40}$. Aunque, en otros ámbitos, todos hemos visto como una de las consecuencias más palpables del 11 de septiembre ha sino la destrucción esa ilusión de seguridad, por lo que sí se continua por el camino de limitar las libertades con el fin de preservar la seguridad, en la medida en que ésta no puede garantizarse se está contribuyendo a la perdida de la confianza en el orden democráticamente legitimado.

En nuestro ámbito de estudio, conviene destacar que la restricción de las vías legales de entrada inmigrantes en los países desarrollados, como Europa occidental, América septentrional y Canadá, iniciado a partir de los años setenta, ha puesto las bases para el nacimiento de este nuevo y floreciente mercado criminal, el tráfico de seres humanos, que es organizado y estructurado como una verdadera y propia industria del ingreso clandestino sofisticada y con apoyos políticos y recursos económicos en los países de origen, tránsito y destino ${ }^{41}$.

Así, el traslado de emigrantes desde sus países de origen hasta los destinos elegidos en Europa paralelamente al tráfico a pequeña escala en el que están implicados pocos individuos, existe poderosas redes clandestinas que facilitan el viaje a cambio de elevadas sumas de dinero. En este mercado criminal operan organizaciones y delincuencia de tipo mafioso, fuertemente coordinadas a nivel trasnacional, evidenciándose el peligro de que el tráfico de los seres humanos, posibilite la creación de nuevas relaciones entre organizaciones criminales de diversa nacionalidad, extendiéndose a tráficos ilícitos más consolidados, en particular como el de la droga o las armas, surgiendo así, nuevas oportunidades delictivas.

No obstante, el tráfico de seres humanos, constituye no sólo un problema de carácter de crimen trasnacional, sino también una de las formas más evidentes y dramáticas de violación de los derechos humanos ${ }^{42}$, se trata de una nueva modalidad de esclavitud, que garantizan los beneficios ingentes de los traficantes a través de la explotación económica de los inmigrantes clandestinos. En la búsqueda de mejores condiciones de vida miles de inmigrantes son introducidos en los países de destino por personas que no tienen escrúpulos que se encargan de introducir mano de obra en el mercado violando gravemente los derechos de los inmigrantes, que suelen habitar en tugurios, están desnutridos y sin servicios sociales. En ocasiones los emigrantes sólo pueden pagar una parte del precio y retrasar el pago hasta que los esperados ingresos de su nueva vida les permitan cancelar la deuda. Si el dinero no llega, las mafias ponen en marcha distintas fórmulas de extorsión que desembocan en la explotación sexual, en secuestros o en asesinatos. También existe el riesgo de que estos inmigrantes que están desprovistos de visado, con documentos falsos o simplemente sin documentos del país de origen, sean utilizados por la criminalidad organizada para el trasporte de droga y el contrabando a los países desarrollados.

Según datos aportados los L'International Center for Policy Development de Viena, cada año son introducidas ilegalmente unas 400.000 personas en el continente europeo. Se estima que en la actualidad los inmigrantes clandestinos que viven en la

${ }^{40}$ Ibídem, pág. 193.

${ }^{41}$ Así, se pronuncia la Commissione Parlamentare d' inchista sul fenómeno della mafia e delle altre asociación criminali similari, Relazione sul traffico degli esseri umani, aprovata dalla Comissione in data 5 dicembre 2000, pág. 14 .

${ }^{42}$ Ibídem, pág. 15. 
Unión Europea son de 3 a 8 millones; en la práctica cada tres inmigrantes que entran en Europa, uno utiliza la vía clandestina. Las organizaciones no gubernativas, estiman que el numero de mujeres que son objeto de tráfico destinado a una posterior explotación sexual son entre 1 y 2 millones al año. En Europa Occidental serían unas 500.000, solamente en Ucrania un número igual al citado cuantificaría las víctimas potenciales de este mercado ilícito. En Japón se piensa que son unas 100.000 mujeres explotadas con fines sexuales, en Tailandia y Filipinas siempre es más elevado el número de los menores involucrados en este tipo de explotación. La Organización Internacional del Trabajo estima en 120 millones el número de niños de edad comprendida entre 5 y 14 años sometidos a trabajos forzados y denuncia la existencia de una venta y de un comercio de menores por parte de organizaciones criminales con contactos internaciones. En Asia, según UNICEF, cerca de 1 millón de niños son explotados en el mercado del sexo, según el Center for the Protectión of Children's rights, 800 mil serían los menores utilizados a tal fin sólo en Tailandia. Asociado al ingreso ilegal, y la sucesiva explotación sexual o laboral de los inmigrantes, se calcula que el número de esclavos modernos estaría entre 27 y 200 millones de personas. Los beneficios ilícitos de este tráfico de carne humana, oscilan entre 7.000 (según la Organización mundial de la Inmigración) y 13.000 (según la Antislavery International de Londres) millones de dólares anuales ${ }^{43}$.

Precisamente la falta de una planificación global, integral y unida ha traído hasta el momento como resultado un incremento de tráfico ilícito de personas y la violación de los fundamentales derechos humanos. La inmigración internacional si no viene regulado debidamente a través de políticas equitativas que tengan como finalidad evitar injustos dualismos en materia de salarios y beneficios sociales, puede representar una seria amenaza para la capacidad de las instituciones sociales existentes, por lo que debe afrontarse con éxito este fenómeno, tanto en la nación que exporta mano de obra como en la que importa ${ }^{44}$. Ahora bien ello no justifica que, en los países desarrollados en la actualidad se otorgue una mayor importancia a la lucha contra la inmigración clandestina, al estar más directamente unida a las políticas de seguridad nacional o internacional, que a la lucha contra el tráfico de seres humanos que suponen una lesión directa contra los derechos humanos.

\section{DIFERENTES FINALIDADES CONTEMPORÁNEAS DEL TRAFICO O TRATA DE SERES HUMANOS EN EUROPA}

El tráfico o trata de personas se desarrolla para atender a las demandas que provienen de los ámbitos en los que existe esclavitud en nuestras sociedades contemporánea. La trata, como hemos manifestado anteriormente, se considera como un fenómeno global de tráfico de seres humanos con el fin de la explotación, siendo uno de las más crueles violaciones en la actualidad de los Derechos del Hombre. Puede afirmase que, aunque, por una parte, la pobreza, el desempleo, así como la ausencia de educación y acceso a las fuentes de recursos constituyen las causas subyacentes de la trata de seres humanos, por lo que siempre hay personas dispuestas a arriesgarse a caer

\footnotetext{
${ }^{43}$ Ibídem, págs. 10 y ss.

${ }^{44}$ PEDRO R. DAVID, Globalizzazione, prevencione del delitto e giustizia penale, GIUFFRÉ
} EDITORE, 2001, pág. 139 
en manos de traficantes para mejorar sus condiciones de vida, por la otra, existe al mismo tiempo, en los países industrializados una tendencia a demandar mano de obra para trabajos poco cualificados, placeres sexuales a bajo precio, etc., viéndose facilitada por el fenómeno creciente de la inmigración económica en busca de empleo.

En la actualidad constituye un fenómeno de carácter estructural y no sólo circunstancial, que afecta a determinadas personas y tiene importantes consecuencias sobre la estructura social, económica y organizativa de nuestras sociedades, que se ha favorecido por la universalización y las nuevas tecnologías. Los traficantes utilizan gran variedad de métodos para transportar a sus víctimas. Actúan a veces a través de agencias de colocación en apariencia legales, agencias de viajes, empresas de entretenimiento o agencias matrimoniales. Con esta actividad, la trata pretende dar respuesta a la demanda de las modernas formas de explotación de seres humanos que son:

\section{TRATA CON EL FIN DE LA EXPLOTACIÓN SEXUAL}

Los mercados del sexo han estado en mayor medida alimentados en los últimos años por la inmigración clandestina. La explotación sexual de mujeres extranjeras es una de las prácticas ilegales más extendidas en Europa, donde más de un $50 \%$ de las prostitutas proceden de países de fuera de la UE. El tráfico de mujeres en el Viejo Continente crece cada año. En el 2001 se calcula que hay una 500.000 jóvenes víctimas de estas redes ilegales que además de venir engañadas son devueltas a sus países sin ayuda psicológica y como inmigrantes sin papeles. La piedra angular de este mercado, casi siempre anárquico y privado de regulación, está también en la condición de fuera de legalidad de las mujeres que trabajan en la prostitución. Este contexto social y cultural propicia que las víctimas sean una mercancía para la explotación, sufriendo horribles abusos, que son cuatro veces más graves y más frecuentes en mujeres extranjeras que en mujeres prostitutas locales ${ }^{45}$.

La presencia de mujeres privadas de un estatus jurídico, a la merced de importantes explotadores, se revela como la causa principal del crecimiento de la oferta de prestaciones sexuales por debito no solamente en Europa y en los países desarrollados, sino en todo el mundo. Esta violación de los más elementales derechos fundamentales se encuentra tanto en Europa como en Asia, en Rusia como en Japón ${ }^{46}$. Otro elemento que favorece la difusión de trata con el fin de la explotación sexual es el valor excesivamente elevado del mercado que conlleva la prestación sexual respecto a otras prestaciones físicas. Comparadas con otro tipo de actividades no cualificadas, la venta de servicios personales de naturaleza sexual son muy rentables ${ }^{47}$. Estas enormes

${ }^{45}$ Sin embargo, en los países europeos en los que la prostitución está reglamentada, la cuota de mercado gestionada ilegalmente aunque bastante menor también está en expansión. Entre otras razones se debe a que legislaciones que han adoptado la vía de la reglamentación no prevén, por ahora, la posibilidad de regularización de las mujeres inmigrantes para ejercer la prostitución, dejándoles en la ilegalidad y privadas de protección, lo que les lleva a ser más vulnerables a las presiones para la explotación.

${ }^{46}$ ARLACCHI, P., Schiavi. Il nuovo traffico di esseri umani, Rizzoli, 1999, pág. 82.

${ }^{47}$ La INTERPOL estima que una prostituta gana 120.000 dólares al año para su explotador, de este dinero recibe una parte irrisoria, que les permite mantenerse. La policía alemana estima que una joven prostituta inmigrante de Rusia gana una media de 7500 dólares al mes: de los que 7000 se queda el 
ganancias representan un primer plano en la economía planetaria, promoviendo la explotación integral del cuerpo con la perdida de la dignidad humana de la víctima. La relación entre la demanda y la oferta tiene lugar según la lógica del máximo beneficio para los criminales, que se encuentran y afrontan riesgos más reducidos que respectos a otros mercados criminales (drogas o armas). Las penas son generalmente leves, las leyes son poco aplicadas y la cooperación internacional en este campo está poco desarrollada.

La captación de las víctimas se hace por diversas vías. El supuesto arquetipo de trata con el fin de la prostitución consiste reclutar a jóvenes mediante el engaño, es decir, ofreciéndolas un trabajo digno y bien remunerado, falsas promesas de matrimonio, etc., en los países de destino, que evidente no existe. Después de la fase reclutamiento, las víctimas, sufren un verdadero secuestro de la persona, se les somete a violencia física, psíquica y sexual, chantajes y engaños de todo tipo, con el fin de tenerlas privadas de libertad de autonomía de pensamiento, de acción y de movimiento.

Los grupos criminales se coordinan en las varias fases del negocio. La partida, el viaje, el destino y algún tipo de explotación final son organizados cuidadosamente, el mecanismo usado cambia según los diversos contextos de llegada o tránsito. Así, generalmente, mientras que los comercios ilícitos de más larga distancia son iniciados y gestionados por formaciones criminales especializadas y es independiente de macro fenómeno demográfico y social, en los territorios limítrofes la existencia de miles de mujeres destinadas a la prostitución forzada tienen lugar a través de la manipulación de los movimientos migratorios ${ }^{48}$.

Por lo que se refiere a España, la explotación sexual no es un fenómeno nuevo, pero desde los años 80 y 90 ha visto modificar su estructura, la modalidad de ejercicio, y sus autores, como consecuencia del crecimiento de flujos migratorios. El mercado de la prostitución representa la más notable y visible actividad de la explotación de que son objeto mujeres, un $92 \%$ de las prostitutas son extranjeras, frecuentemente menores, provenientes sobre todo de Europa Centro-oriental, de África, de Asia y de América Latina. En un año se han duplicado las redes desmanteladas por el departamento de extranjería de la policía dedicada a la explotación de la prostitución (de 41 en el 1998 a 82 en 1999) ${ }^{49}$. El mercado de la prostitución, en la práctica, ha permitido a los grupos criminales nacionales extranjeros acumular una notable riqueza, ocupar espacios criminales liberados por las organizaciones delincuentes autóctonas, extender sus actividades criminales a otros mercados ilícitos, y consecuentemente, iniciar una progresiva erradicación por el territorio.

\section{TRATA PARA LA EXPLOTACIÓN LABORAL}

El trabajo sumergido margina a los sujetos del mercado laboral oficial, en ciertos aspectos representa un puente entre la economía lícita e ilícita, porque para legitimar y ocultar la esclavitud se sirven de sistemas plenamente aceptados de formación de relaciones laborales. Lo cierto es que, los empresarios prefieren a los trabajadores irregulares y explotarlos -alterando la competencia regular- porque, de este modo, se les

propietario del local que explota a la mujer. De los 500 dólares restantes, son para pagar el alojamiento, comida y vestido, la mujer solo recibe 12 dólares.

${ }^{48}$ ARLACCHI, P., Schiavi. Il nuovo traffico di esseri umani, Rizzoli, 1999, pág. 90 y s.

${ }^{49}$ Les formes contemporaines désclavage dans six pays de l'Únion Européene, Études et Recherches, UE, 2000, pág. 33. 
reducen los costes de producción. Los sectores en los que opera buena parte de la trata de inmigrantes con el fin de la explotación laboral principalmente son: los trabajos domésticos, agrícolas, construcción, sectores de la hostelería, en fabricas de pieles y textiles y el trabajo ambulante.

A diferencia de otro tipo de mercados la relación entre el traficante y la persona traficada, se funda esencialmente en lo una explotación consensual. Más que la violencia, aunque no completamente ausente, en este tipo de mercado, la persona explotada sufre frecuentemente engaño o chantaje. Entre las prácticas más habituales se encuentran por ejemplo, la amenaza de no restituir los documentos requeridos hasta el pago de la estimación completa del debito, la amenaza de realizar acciones violentas a los familiares en la patria, la atribución de un salario netamente inferior respecto al pactado, o en fin, desarrollar un trabajo diverso al acordado ${ }^{50}$.

En términos generales puede constatarse que en este país se abusa diariamente de la indefensión de los sin papeles, lo que plantea la necesidad de intervenir en los espacios donde se produce la explotación y, obviamente, con medidas punitivas hacia quien comete ese delito y no contra quien la sufre ${ }^{51}$. Es conocido dónde se concentran un mayor número de inmigrantes, dónde se prodigan relaciones de semiesclavitud, y, por tanto, dónde es necesario un aumento de las medidas inspectoras en materia de seguridad. Pero, tampoco se me escapa que el aumento de flujos migratorios, no constituye el nacimiento del trabajo sumergido y ni de la economía sumergida en España. De hecho antes del aumento migratorio a través de nuestro país, el trabajo sumergido constituía una característica estructural de nuestra economía. Con el aumento de la movilidad de las personas, provenientes de los países en vía de desarrollo y en transición, simplemente se ha cubierto el vacío de mano de obra dispuesta a aceptar: salarios bajos respecto a los establecidos en los contratos laborales con los nacionales, horarios de trabajo prolongados, trabajos duros que se desarrollan en condiciones desprovistas de las medidas de protección higiénico-sanitarias y con una seguridad precaria, sin seguro de laboral, etc. Conviene subrayar que esta economía sumergida, sin embargo, constituye por sí uno de los factores de atracción de los flujos irregulares a través de nuestro país. De hecho, la mayoría de las personas que llegan a España tanto de forma irregular como regular, con o sin recursos propios, recurren al mundo del trabajo sumergido, como una alternativa a la delincuencia, se trata de ganar el dinero necesario para recuperar la inversión, pagar o amortizar las deudas y un recurso para hacer frente a las primeras necesidades.

${ }^{50}$ No obstante, en algunos casos, como el de las trabajadoras domésticas existen verdaderos secuestros. Sus empleadores limitan expresamente su libertad de entrar y salir, amenazándolas con que si no realizan el trabajo doméstico dada su situación de irregularidad serán denunciadas para que las arresten y expulsen. Sin embargo, en otras ocasiones vienen con un contrato laboral, por ejemplo, se calcula que en Londres son al menos un millar las esclavas domésticas, todas ellas cubiertas por un contrato de empleo y del reconocimiento de tal contrato por la oficina de inmigración británico al momento de su llegada al país $^{50}$. Normalmente son reclutadas en su país de origen por las agencias de empleo doméstico, otras no vienen para ejercer el empleo doméstico, pero son víctimas del engaño de traficantes. En España la mayoría de las empleadas domésticas son de origen Latinoamericano (dominicanas y peruanas) y de Marruecos.

${ }^{51}$ El artículo 55 de la actual ley, que favorece la regularización de los y las inmigrantes que denuncian estar sometidos al abuso por alguna persona o red 


\section{TRATA CON EL FIN DE LA MENDICIDAD}

La mendicidad constituye otro mercado ilícito en el cual se explota sobre todo menores. Estos últimos privados de sus elementales derechos se les obliga a vivir en barracas situadas en al periferia de la ciudad, al ejercicio de la mendicidad en las estaciones de las grandes ciudades y calles con numeroso tránsito. Su obligación de ganarse una determinada suma, requiere que en ocasiones se dediquen a realizar pequeños hurtos de monederos, bolsas y objetos de particular valor.

\section{TRATA PARA MATRIMONIOS FORZADOS}

El matrimonio tiene aquí por finalidad burlar las legislaciones nacionales de autorización de salida o entrada en un territorio y reclutar a jóvenes mujeres. Para poder salir del país y de la situación de extrema pobreza algunas mujeres se ven forzadas a casarse. Los traficantes confeccionan unos catálogos de mujeres, en las que se incluyen candidatas por voluntad propia, o bien la mayoría de supuestos son los propios familiares quienes prestan el consentimiento. A través de estos catálogos determinados sujetos que habitan en los países del denominado primer mundo eligen a una de ellas con el fin de casarse. El traficante actúa como intermediario entre las partes, pagando o prometiendo una cantidad de dinero a su familia, cuando se celebre el matrimonio forzado. Una vez en el país de destino, a las mujeres se las somete a la explotación, la intimidación y al aislamiento. De hecho, una vez casadas son obligadas a trabajar sin remuneración, a procrear, sufriendo todo tipo de maltrato psíquico y moral para satisfacer a su marido. En ocasiones, son los propios familiares, que siendo ya nacionales de países desarrollados, fuerzan a una mujer a casarse con un sujeto de su país de origen a cambio de dinero, con el fin que éste pueda obtener la residencia legal y posteriormente la nacionalidad. Señalar que, los supuestos de matrimonios falsos celebrados para eludir las leyes de inmigración, siempre que sean voluntarios por ambas partes, aunque se celebren por precio, no suponen ningún tipo de trata, en todo caso, sería un supuesto de tráfico de inmigrantes.

\section{TRATA DE NIÑOS A TRAVÉS DE ADOPCIONES ILEGALES}

En el caso de que las víctimas sean niños, se ha constatado asimismo el uso por parte de los traficantes de procedimientos de adopción, para introducirlos en el país de destino con el fin de explotarlos posteriormente laboralmente, sexualmente o en la mendicidad.

\section{TRATA CON CUALQUIER OTRO FIN DEGRADANTE}

Los traficantes utilizan los más variados medios para conseguir el reembolso del precio del viaje en aquellos supuestos en los que el inmigrante carece de capital propio. Así, a menudo, en el Estado de destino, suelen someter a los inmigrantes a formas de servidumbre, incluida la servidumbre por deudas, que a menudo entrañan la comisión 
de actividades delictivas o cualquier otra fin degradante para poder pagar su viaje. La mayoría de los casos se utiliza a los inmigrantes para:

\subsection{Introducción de droga}

En ocasiones se les prevé de documentos falsos, para que puedan entrar al país de destino con una visa de turistas por los pasos habilitados para tal efecto, en otras se les proporciona el viaje en una patera, accediendo al país de destino sin pasar por la frontera, en ambos casos a cambio de que una vez allí entreguen la droga a los traficantes.

\subsection{Tráfico de órganos}

La trata de personas para la extracción de órganos no existen pruebas de que exista en España. Pero en otros países está constatado que es una forma en que el inmigrante pague el coste del viaje de origen al de destino. El inmigrante es sometido a una difícil y delicada operación, sin disponer probablemente de la capacidad de entender y de querer, porque no tiene la información suficiente y desconoce el riesgo.

A modo de conclusión podemos decir, por una parte que, en la actualidad, como he afirmado antes en las sociedades del primer mundo la trata de seres humanos se ha desarrollado e impulsado por el aumento de flujos de inmigración irregular, de ahí se utilicen los instrumentos jurídicos de control y represión de estos flujos migratorios como medidas preventivas para contrarrestar el fenómeno de la trata, otorgándolos siempre un papel prioritario. Pues bien, en contra de esta tendencia, entiendo que la trata de seres humanos para la explotación sólo es un medio utilizado y originado por la existencia de sectores o ámbitos que demandan a personas para que realicen actividades en condiciones de esclavitud, por lo si realmente se quiere erradicar la trata de seres humanos deben realizarse acciones tendentes a intervenir y reprimir los espacios donde se produce la explotación. Además es una forma también de limitar la entrada de personas irregulares, que llegan atraídas por la demanda de contratación de mano de obra ilegal. Por la otra, la existencia de normas rigurosas y restrictivas para acceder al territorio, hace posible la existencia gran numero de inmigrantes que debe vivir en la clandestinidad, lo que hace difícil que puedan disfrutar activamente de los derechos y garantías que les son formalmente reconocidos, quedando así relegados a la indefensión y a la fácil explotación por parte del resto de la sociedad civil.

\section{LA POLÍTICA MIGRATORIA Y LA INMIGRACIÓN CLANDESTINA}

Los movimientos migratorios de población, aunque por la alarma social creada pudiera parecer que se trata de un fenómeno nuevo, son tan antiguos como la humanidad misma. Desde que el hombre es hombre ha estado moviéndose de unos lugares a otros en busca de nuevos asentamientos que le ofreciesen mayor seguridad o unas mejores condiciones de vida. El actual incremento de los flujos migratorios a Europa con pretensiones de estabilizarse en el país de destino a diferencia de otros momentos históricos se debe no sólo al desplome económico y social producido en los países del Este, y las guerras producidas por la exacerbación nacionalista, sino que 
además, como hemos tratado poner de manifiesto antes, obedece a que el proceso de globalización acrecienta la profundidad de la brecha que separa el desarrollo económico y social entre los países emisores y los países receptores de inmigración. Ello es así, entre otras razones por el volumen creciente y la distribución asimétrica de la población afectada, la explosión demográfica, es decir, la superpoblación (que la Iglesia católica se obstina irresponsablemente en promover), la penetración en todos los rincones del planeta de los valores que legitiman el logro individual y la movilidad social, así como la creciente eficiencia y accesibilidad de los medios de trasporte, que facilitan cada día más la movilidad geográfica de las personas.

Ante este fenómeno, la política migratoria constituye una actividad estatal y europea que tiene como objetivo gestionar de modo adecuado los flujos migratorios. Así, en la Unión Europea, a partir de los años setenta, los movimientos migratorios se han convertido en objeto de control y rechazo por parte de los distintos Estados miembros. De hecho, las políticas migratorias de los gobiernos europeos convergen hacia tres objetivos claros: un control férreo de los flujos migratorios, dejar abierta la posibilidad de admisión de trabajadores para satisfacer las necesidades coyunturales de sus mercados y lograr una adecuada integración social y económica de las minorías, dándose prioridad, en cualquier caso, al primero de estos fines. A tal efecto el tratado de Schengen, ${ }^{52}$ articula un sistema de blindaje frente al exterior, del que puede ser muestra en España las duras normas sobre la inmigración.

Tradicionalmente, la Unión Europea había ejercido un control sobre los flujos, persiguiendo que no aumente desmedidamente la demanda de trabajo con la consiguiente caída de los salarios, es decir, permitir una cierta inmigración para responder a las necesidades coyunturales del mercado de trabajo ${ }^{53}$. Estos argumentos económicos y de mercado son avalados por las estadísticas de la UE: en los próximos diez años tendrán que entrar 12 millones inmigrantes para mantener fabricas abiertas y los costes de la seguridad social cubiertos ${ }^{54}$. Lo cierto es que en nuestro país, tenemos la

52 Como señala DE LUCAS, J., "Fronteras de los derechos humanos: racismo y estrategias de legitimación en la Unión Europea”, en Cuadernos Constitucionales de la Cátedra Fadrique Fuirió, n 17, Valencia 996, pág. 40 y s. Realmente la filosofía de Schengen responde a un modelo de exclusión institucional, al la promulgación de normas por parte de la UE que en la práctica son un modelo excluyente de ciudadanía, que convierte a los extracomunitarios en súbditos y multiplica su vulnerabilidad, dado los límites introducidos en el ejercicio de sus derechos. En el mismo sentido, DE GIORGI, A., Zero Tolleranza. Strategie e pratiche della societá di contollo, Derive, 2001, pág. 59 y s., señala que este dispositivo desarrolla una estrategia de prevención frente a la población migrante, una filosofía de control e eliminación de la libertad que se base en la representación del inmigrante como un portador de peligro; un peligro que constituiría en cuanto a tal, no como individuos determinados, pero como pertenecientes a una categoría de sujetos <<un riesgo〉> los extranjeros.

${ }^{53}$ En la mentalidad colectiva pesa que "inmigrante regular" no debe ocupar los puestos de trabajo que ningún "ciudadano" está dispuesto a hacer, con un salario mínimo, en condiciones muchas veces infrahumanas, no es relevante su cualificación, serán los trabajadores de los plásticos, del servicio doméstico, la economía sumergida, la prostitución, etc. Según un informe de la Organización Internacional del Trabajo presentado el 8 de marzo del 2000 en Ginebra, de los trabajadores extranjeros que residen legalmente en España el 36\% son rechazados por las empresas debido a su origen. El colectivo más discriminado es el de los magrebíes. La OIT calcula que el $37 \%$ de los trabajadores inmigrantes que están en activo en España son marroquíes.

${ }^{54}$ Solamente España en el año 2025 necesita 12 millones de inmigrantes. Para este mismo período, y en el caso de no variar la tasa de fecundidad, el conjunto de la Unión Europea necesitaría un aporte de mano de obra estimado en 159 millones de inmigrantes. 
natalidad más baja del mundo ${ }^{55}$. Por ello, los expertos de la ONU han manifestado que España tendrá que aceptar 170.000 emigrantes anuales en el próximo medio siglo, para mantener constante su población actual. Esta cifra aumenta a 240.000 inmigrantes anuales para mantener el actual nivel de vida y la proporción de cuatro trabajadores activo por un jubilado. Pero, es que además, los inmigrantes con independencia de su cualificación, entrarán en España con un destino laboral prefijado dependiendo de la demanda por sectores: tantos para agricultura, tantos para la construcción y tantos para servicio doméstico, por lo que la realidad nos demuestra que la primera discriminación tiene lugar en los propios flujos como vía preferencial. Después, una vez que están en el territorio de destino, sufren una discriminación laboral, que se inicia ya en la limitación jurídica de sus derechos y se evidencia también en la asignación a puestos de trabajo al margen de la cualificación efectiva que aportan.

Esta perspectiva interesada, que manifiesta las necesidades del mercado en determinados sectores y que pone de relieve que es la única vía posible para mantener los pactos de pensiones más allá del 2010, determina que el inmigrante regular es entonces el que interesa al mercado, lo que choca frontalmente con los derechos humanos y es una respuesta ineficaz frente a los actuales flujos migratorios, en la medida en que siempre existirá un contingente que continuara al margen de las exigencias del mercado ${ }^{56}$.

En este sentido, parece que la política de inmigración a la vista de los resultados, ha mostrado ineficaz la vinculación entre la regularización y las necesidades del mercado de trabajo. Es evidente que el fenómeno migratorio desborda la dimensión económico laboral, lo que conlleva una serie de costes sociales y políticos mayores que los beneficios económicos. Los flujos son cada vez menos estructurados y organizados, son imprevisibles, es decir, cada vez menos controlables por los Estados. La existencia de datos recientes, avala las previsiones de que, en los años venideros, se producirá una mayor importancia en el total de la población inmigrante de las personas pertenecientes a terceros países (norte de África, países de África subsahariana, y China), así como su posible aprovechamiento en los mercados de trabajo de las economías europeas, augura que el asentamiento entre las poblaciones nacionales de un sector de inmigrantes irregulares tendrá, como ya es en EEUU, una naturaleza estructural.

Esta previsión de continuidad de la presión migratoria existente, supondrá un incremento de flujos irregulares que utilizan las redes de tráfico de personas, para las que el territorio español no es sólo un punto de destino, sino también de tránsito. Ante ello, existe una profunda división de los ciudadanos de este país. La reiterada aparición de las pateras provoca una impresión de avalancha que nos lleva a creer que el número de inmigrantes que están entrando es excesivo, o no es asumible por el Estado español. En realidad no representa un aumento de población inmigrada que supere lo que parecen ser las necesidades de inmigración laboral actuales, y mucho menos lo que se prevé como necesidades futuras. El único número realmente excesivo en este asunto, el

${ }^{55}$ En un estudio publicado por la ONU de octubre de 1999 sobre las tendencias democráticas en los próximos cincuenta años sitúan a España como un país cuya población experimentará el mayor envejecimiento del mundo: si se mantiene la tasa de fertilidad actual (1,07 niños por mujer en edad fértil), la media de edad en nuestro país se convertirá en la más elevada del planeta en el año 2050, con 54,3 años de medida, y de 39,5 millones de españoles pasaremos a ser 30,2 millones en esa fecha.

${ }^{56}$ DE LUCAS, J., “¿Qué política de inmigración? (Reflexiones al hilo de la reforma de la Ley de Extranjería en España)”, en Tiempo de paz, n 55, 1999, pág. 14 
dato atroz, es el de los muertos por naufragios de pateras que se produce cada año más de 1000 muertos sólo en la zona de Gibraltar ${ }^{57}$.

Resulta fundamental asumir la importancia que tiene la inmigración, dado que los inmigrantes no son el mayor problema del siglo que comienza, sino que en numerosas ocasiones sirve para solventar nuestros problemas estructurales. Es importante aclarar que, ante el fenómeno de la inmigración, es muy peligroso pretender justificar una posición dando un mensaje alarmista que intenta reflejar de manera irresponsable una especie de pequeña invasión sobre la que hay que actuar. Esta perspectiva, que ensalza el discurso de los más racistas y xenófobos y que permite hacer público sin miedo, sin ninguna moderación, el rechazo de la inmigración, ha sido el germen en otros países de nuestro entorno europeo, de la consolidación de posiciones políticas de extrema derecha -véase el caso de Francia, Austria, Holanda, Bélgica o Italia-. En el caso de este país, desde el Gobierno se mantiene esta visión deformada de la inmigración como un problema de orden público y de seguridad, como una amenaza para el mercado laboral y para "la propia identidad". Incidiendo, últimamente, en la idea de los extracomunitarios como "ejercito de reserva de la delincuencia" ${ }^{\text {, }}$, como causa de la inseguridad ciudadana, vinculada a las formas de delincuencia que merecen más rechazo social, lo que se traduce en la su presentación como un problema de orden público, frente a la cual hay que actuar.

Esto ha motivado que entre nuestras fronteras, en lugar de ofrecer una auténtica política de inmigración, se ha hecho política con el tema de la inmigración, convirtiendo esta materia en un instrumento de lucha electoralista y partidista. Prueba de ello, han sido las peripecias que ha sufrido en su reforma la Ley de Extranjería. La LODYLE 4/2000 intentó cambiar esta situación, estableciendo una regulación que es más o menos equivalente a las leyes que existen en la mayoría de países comunitarios, donde se frena la nueva inmigración -eso es verdad-, pero se reconocen amplios derechos a quienes llevan varios años en el país, buscando su integración para evitar el racismo y los conflictos sociales. Al margen de algunas dificultades técnicas, podía afirmarse que en la Ley 4/2000 ganaban derechos los extranjeros "regulares" y avanzaban los derechos de los "irregulares".

Sobre esta Ley se han emitido mensajes o pronósticos que podían calificarse de "xenofobia institucional" al advertir que España se convertiría "en un coladero", "en una plataforma de mafias", o el riesgo de presión inasumible sobre los servicios sociales que deberían hacer frente a una avalancha de peticionarios de derechos. Ante todo se ha acusado de irresponsables las "desmedidas concesiones a la inmigración irregular", excesos por otra parte incompatibles con las exigencias de la política europea ${ }^{59}$. Por el

${ }^{57}$ TERRADILLOS BASOCO J., "El derecho de la globalización luces y sobras”, op., pág. 209; el mismo "El Estado y los conflictos sociales: la función del sistema penal”, op. cit., pág. 29

${ }^{58}$ Cfr., críticamente, DE LUCAS, J., "Fronteras de los derechos humanos: racismo y estrategias de legitimación en la Unión Europea”, op. cit., págs 50 y ss.

${ }^{59}$ En concreto las críticas se centran en cuatro aspectos: 1. La equiparación en el reconocimiento de derechos de salud, educación, asociación, reunión, participación pública o ayudas a la vivienda, a todos los inmigrantes, y sobre todo la inclusión de algunos de esos derechos a los irregulares, tal y como aparecen en los capítulos I y III (arts.4 a 16, junto a las garantías jurídicas reconocidas a todos en los arts. 19 a 21). 2. Los procedimientos de adquisición del permiso de residencia que suponía reconocer situaciones de hecho, irregulares, consolida rapidez - dos años - mediante el empadronamiento como medio de prueba (art.13.1). 3. La extensión de derecho a recurrir la denegación no razonada del visado. 4. La regularización generosa del derecho a la reagrupamiento familiar (art. 18). Por el contrario, entiendo que, los 
contrario, se puede decir que, el sistema de entrada seguía siendo el que era (desde 1985), y continuaba siendo muy inaccesible. Se establecían más facilidades para quienes vienen por reagrupación familiar, pero para quienes deseaba venir a nuestro país a trabajar, la entrada regular continuaba siendo muy difícil. Las condiciones siguen siendo disponer de una oferta previa de empleo y con ella solicitar el visado de entrada en un consulado español de su país de origen. Esta ley simplemente trataba mejor a los inmigrantes que ya estaban aquí, pero no ampliaba las vías legales para la inmigración $\mathrm{y}$, por tanto, era incongruente decir que provocaba una mayor entrada de inmigrantes. Salvo que se nos estuviera diciendo (y éste parecía ser el mensaje) que el mejor sistema para controlar la entrada de inmigrantes es no tratar muy bien a los que ya están dentro. Pero incluso esta premisa sería errónea, porque nada indica que las personas hagan su opción migratoria en función del conocimiento que tengan de las condiciones legales que se van a encontrar en el país receptor

Pues bien, desde el triunfo electoral del PP por mayoría absoluta, cuyo programa electoral defendía la reforma de la Ley de Extranjería, se ha alimentado, con una impresionante carga de irresponsabilidad y demagogia, la inseguridad y el miedo al "otro", desencadenantes ciertos del racismo y la xenofobia. Como consecuencia de esta campaña, la reforma no se hizo esperar, avalada por los siguientes argumentos, supuestamente legitimadores, esgrimidos por el partido que ocupa el Gobierno: primero, la Ley 4/2000 se encuentra al margen de las directrices marcadas por la Unión Europea en los Acuerdos de Tampere; segundo, la previsión de solicitudes de regularización se ha desbordado, provocando además el denominado "efecto llamada", y por último, la justificación de modificación legislativa tiene como fin la lucha contra las mafias.

Lo que sí es cierto es que con la última Ley 8/2000 de 22 de diciembre, el Gobierno fractura definitiva del consenso social sobre la inmigración, fomentando un arsenal jurídico, que se caracteriza por retornar a la normativa anterior y está orientado precisamente a desestabilizar socialmente, a deslegalizar, a crear las condiciones que arrojan a los inmigrantes a una situación que les constituya efectivamente como problema, como amenaza en los distintos órdenes. La reforma responde a una visión estrictamente policial de la inmigración, donde el control de la entrada y la ilegalización de los irregulares se convierten, en sí mismos, en los elementos básicos de la política

aspectos más criticables, además de las numerosas incorrecciones técnicas, esta Ley de Extranjería, como expresó en su momento MORENO DÍAZ, J.A., “ La nueva Ley de Extranjería. Claroscuros de una reforma”, en Revista de Derecho Social, n 9, 2000, págs. 245 y ss., asesor Confederal de migraciones de CCOO, son que: 1. Mantenía la vinculación entre el permiso de trabajo y permiso de residencia, pese a que ha sido una exigencia constante en todas las reivindicaciones desvincular ambos conceptos habilitando un único permiso de residencia que, obviamente, deberá habilitar para trabajar de forma automática. 2. Establecía una nueva necesidad de autorización administrativa para aquellas empresas que deseen contratar trabajadores extranjeros, sin determinar si deberá ser una autorización genérica para la empresa o individualizada por cada oferta de trabajo que se plantee. 3. Se perdía la oportunidad de articular, de forma efectiva, el derecho de voto de los extranjeros en las lecciones municipales cuando lleven en España un periodo significativo de arraigo, especialmente relacionado con el permiso de residencia permanente, lo cual impidió abrir la vía para articular la integración política de los inmigrantes como elemento de una integración social. 4. Mantenía elementos negativos en el procedimiento sancionador. Entre ellos: una regulación abusiva de la prescripción de la sanción expulsión, que prácticamente hacía inviable el cómputo de la misma, o el castigar dos veces algunos infractores.5. El mantenimiento del internamiento, esto es, el hecho de que un extranjero se les pueda priva de libertad cuando comete una infracción administrativa por un plazo de 4 días. 
migratoria $^{60}$. Tal concepción, lleva inevitablemente aparejada la proliferación del negocio de las mafias que trafican con personas y la existencia de un mercado laboral secundario, de un contingente de mano de obra de segundo orden y bajo coste salarial — con escasas posibilidades de exigir derechos, dada su inseguridad jurídica- cuando no clandestino y más fácilmente explotable.

En suma, la vía seguida en estos instrumentos jurídicos, más aún la última Ley $8 / 2000$, es presentar el fenómeno de la inmigración como un peligro que se debe combatir, junto con las amenazas a la seguridad interior, desde fronteras exteriores reforzadas para compensar la desaparición de las fronteras interiores, además suponen una reducción de los derechos atribuidos al "contrato de extranjería" respecto al "contrato de ciudadanía". En consecuencia, se pretende atajar el fenómeno a través del control de los flujos migratorios como elemento vertebrador de nuestra política de inmigración, lo que obliga a una muy precisa regulación de las condiciones que habilitan para acceder legalmente a la condición de inmigrante y lo que conlleva que cuanto más estrictos sean los elementos de esta regulación, mayor es el impacto sobre los residentes extranjeros -presentes y futuros- en el territorio español, dado que las oportunidades de quedar "fuera de la ley" aumentan. ${ }^{61}$

El resultado que se produce es el fenómeno, por todos conocido, de la inmigración clandestina (la denominada "inmigración ilegal"). Aquellos inmigrantes que quedan fuera del cupo no les queda otro camino que la patera o camiones y ser "irregulares". Su introducción en el un territorio extranjero se produce a través de mafias $^{62}$, de empresarios sin escrúpulos y de explotadores del trabajo sumergido. Se calcula que entre el 15 y el $30 \%$ de los inmigrantes irregulares demandan los servicios de los traficantes. Pues bien, podría afirmarse que las formas a través de las cuales los traficantes introducen a los inmigrantes en España, va a tener consecuencias que determinan el nacimiento de flujos migratorios, que se distingue unos de otros, no desde un punto de vista cuantitativo, sino por la forma en que llegan, por los costes que el inmigrante debe pagar, por la ruta que debe utilizar, por el hecho de considerar a España como un meta o fin, sino también como una etapa del viaje destinado a terminar en otras naciones, convirtiéndose de esta manera tanto en un país de destino como de tránsito. Así, podemos distinguir entre: los traficantes de seres humanos que introducen a los inmigrantes en forma legal o aparentemente legal. En este caso, a los inmigrantes se les provee de visados temporales regulares o de pasaportes y documentos de ingreso adecuadamente falsificados. Este tipo de entrada en nuestro país es generalmente legal por motivos del turismo o para el desarrollo de un particular tipo de trabajo. La entrada

${ }^{60}$ Parece claro que, se dirige, básicamente, a reducir los derechos de los que ya están dentro, principalmente de aquellos que se hallan en situación de irregularidad administrativa (sin permiso de residencia). Se pretende facilitar su expulsión y reducir las posibilidades que la actual ley les concede para regularizar su situación (además de recortar severamente sus derechos sociales), y el resultado que se espera obtener de ello es la disminución del flujo de inmigración irregular. En definitiva, la razón última de esta reformar es que, el avance en el reconocimiento de los derechos de los inmigrantes regulares debe hacerse a consta de sacrificar los avances respecto a los inmigrantes irregulares. Se trata de convertir en ilegales a los irregulares, de dificultarles -si no impedirles- el acceso a las condiciones del status de legal.

${ }^{61}$ DE LUCAS, J., "La lucha contra la discriminación”, op.cit., pág. 156

${ }^{62}$ El negocio del tráfico de emigrantes es sumamente lucrativo, por pasar en coche o en una embarcación, ilegalmente, a alguien a través de una frontera de Europa Occidental, pueden cobrarse hasta 500 dólares. La OIT estima entre 5000 y 7000 millones de dólares el dinero movido anualmente por el tráfico de emigrantes indocumentados. 
usualmente se realiza por la vía marítima o por la vía aérea, en ocasiones realizando varias escalas. Esta forma aparentemente legal es utilizada por los traficantes para inmigrantes que tienen un capital propio de cierta entidad, que consiste en que estos últimos adquieren una serie de servicios menores respecto a otros inmigrantes. De aquellos otros traficantes que, introducen al inmigrante en el territorio de forma ilegal, en este caso, no están provisto de documentos de identidad tampoco disponen de documentos falsos. Los inmigrantes en este caso, llegan a España por un periodo largo y afrontan un viaje mucho más peligroso respecto a los inmigrantes que entran con la modalidad descrita anteriormente. En el curso del viaje, compuesto en ocasiones de un cierto numero de etapas intermedias, los inmigrantes son objeto de violencia, con la sumisión a todo tipo de vejaciones corporales, la malnutrición, etc. Los precios de estos servicios de tráfico son muy altos, de modo que muchos inmigrantes ilegales tienen que entregar la mayoría o todos sus ahorros. Cuando los inmigrantes no sean capaces de pagar el precio, se convierten a menudo en víctimas de los traficantes, que recurren a su explotación para obtener el "reembolso" del coste del viaje.

Con el fin de frenar este fenómeno se ha introducido en las tres primeras disposiciones de la LO 4/2000 modificaciones que afectan al Código penal: la $1^{\mathrm{a}}$, modifica el artículo 312, agravando la pena del delito de tráfico ilegal de mano de obra; la $2^{\mathrm{a}}$, introduce el Título XV bis en el Código Penal, destinado precisamente a proteger a los inmigrantes de las organizaciones criminales que trafican con ellos, cuyo tratamiento penal es el objeto del presente trabajo; la $3^{\mathrm{a}}$, afecta a los artículos 515, 517 y 518 , considerando asociaciones ilícitas aquellas que promuevan el tráfico ilegal de personas. Aunque, la realidad nos demuestra que hasta ahora los instrumentos jurídicos ya existentes en CP, como el art. 312 cuya finalidad precisamente a impedir la proliferación de estas organizaciones criminales prácticamente no se han aplicado, o incluso, se han pretendido utilizarlos para castigar a quienes, "con su ayuda humanitaria, no fomentan ni facilitan la inmigración, sino que, más humildemente, coadyuvan a la tutela de los derechos exigidos por la dignidad de inmigrante" ${ }^{93}$.

Realmente, se puede constatar, por una parte, en los últimos años han penetrado en este país un número elevado de nacionales de terceros países, y estas presiones migratorias continúan con el consiguiente aumento del contrabando, el tráfico y la inmigración ilegal, debido a un inadecuado régimen legal y la práctica restrictiva administrativa. Por la otra, como resultado de la creciente escasez de mano de obra, tanto cualificada como no cualificada, se ha comenzado a contratar activamente a nacionales de terceros países. Ante esta situación, que es común a toda Europa, debe optarse entre mantener la visión de que la Unión puede continuar resistiendo las presiones migratorias, o aceptar que la inmigración va a continuar y debe regularse adecuadamente, y trabajar juntos para intentar maximizar sus efectos positivos en la Unión, tanto para los propios migrantes como para los países de origen.

Es fundamental que se deje de considerar al fenómeno migratorio como un simple proceso que tiene lugar entre Estados. No debe desconocerse la internacionalización del fenómeno migratorio, de forma que debemos ser conscientes que estamos ante una realidad con evidentes implicaciones internacionales, es decir, ante un fenómeno que no puede ser abordado únicamente de forma individualizada por

${ }^{63}$ TERRADILLOS BASOCO J., "El derecho de la globalización luces y sobras", op. cit., pág. 209; el mismo "El Estado y los conflictos sociales: la función del sistema penal”, op. cit., pág. 29. 
el país de origen ni por el país de destino de los inmigrantes. En este sentido, se hace necesario adoptar una visión global, que tenga en consideración una multiplicidad de factores como la situación de los países de origen, los movimientos de capitales, el desarrollo tecnológico, las redes migratorias y las comunidades de inmigrantes establecidas en los países receptores, entre otros. El diseño de políticas migratorias elaboradas unilateralmente y que se basen únicamente en el cierre de fronteras, está destinado al fracaso y a fomentar la inmigración clandestina. Todo esto explica precisamente la necesidad de una política migratoria centrada en primer término en las causas que están el origen de los actuales movimientos migratorios, sólo así puede darse una respuesta a las transformaciones de los flujos migratorios, que hoy son condición estructural de la sociedad global. Ahora bien, estos medios que ayudarían a gestionar los flujos migratorios sólo pueden hacerse desde un presupuesto de respeto básico a los derechos fundamentales. En resumen, no es un problema estatal, sino planetario, de justicia distributiva. 